УДК 539.4

DOI: 10.15587/2313-8416.2018.146636

\title{
METHOD OF THE RELIABILITY CALCULATION OF ORTHOTROPIC COMPOSITE MATERIALS WITH RANDOM DEFECTS
}

\author{
(C) R. Baitsar, R. Kvit
}

Описано алгоритм розрахунку надійності стохастично дефектних ортотропних композитних матеріалів за умов складного напруженого стану. Розглянуто критерій максимальних макронапружень для композита з довільно орієнтованими тріщинами з переважаючою орієнтачією в напрямку армування. Отримано функцію розподілу руйнівного навантаження композита. Розраховані і побудовані діаграми залежності ймовірності руйнування досліджуваного зразка матеріалу від прикладеного навантаження для різної кількості тріщин і структурної неоднорідності.

Ключові слова: надійність, ортотропний композитний матеріал, імовірність зруйнування, функція розподілу, руйнівне навантаження.

\section{Introduction}

The trends in the development of modern technology are characterized by the widespread use of structures made of composite materials, which often have brittle fracture. Problems that arise in designing and using such structures, necessitate the development of mathematical models that allow obtaining adequate estimates of their mechanical behavior and properties. The stochastic nature of real composites structure leads to the need to construct these models based on the statistical approach. The complex application of known brittle fracture mechanics deterministic solutions and probabilistic and statistical methods is an actual problem in the manufacture of equipment with increased requirements of strength and reliability.

\section{Literature review}

The application of methods of probability theory and mathematical statistics in the problems of composite materials fracture mechanics was developed in a number of authors' works. In particular, in the design and evaluation of the strength and mechanical properties of composite materials in $[1,2]$, the Weibull distribution was used. The author of [3] proposed a statistical approach in the research of composite plates of different weight in polyester reinforced with fiberglass. In paper [4] a numerical simulation and analytical probabilistic methods for the reliability evaluation of composite structures [4] are considered. A statistical model describing the associated deformation and damage of composites with porous transverse isotropic and orthotropic components is proposed [5], and the mechanism of micro-damage of composites is considered, provided that the microstructure of the material is non-uniform. The method of the composite materials reliability predicting under tensile conditions is investigated and a statistical analysis of experimental data has been carried out [6]. Experimental investigations of the composite glass fiber materials tensile strength and the statistical analysis of the results obtained on the basis of the two-parameter Weibull distribution have been carried out in [7].

\section{The aim and objectives of research}

The aim of the work is construction of an algorithm for the reliability calculating (probability of failure) under different loading conditions of orthotropic composite materials with a different number of stochastically distributed defects-cracks that do not interact with each other.

To achieve this aim, the following tasks need to be solved:

- set the fracture criterion of the orthotropic composite in conditions of a complex stressed state, expressed through the components of the macroscopic stresses (stresses averaged over a certain area);

- choose the distribution laws of such statistically independent defects parameters as orientation angle and length;

- get the failure loading distribution function for a composite element with one crack;

- calculate and construct diagrams of the composite failure probability dependence from the applied loading for a different number of defects and different structural inhomogeneity of the material.

4. Algorithm for the probability of failure calculating (reliability evaluation) of stochastically defective composite materials

Let's consider the plate, the material of which is composite, and consists of a matrix (binder) and reinforcing elements (Fig. 1).

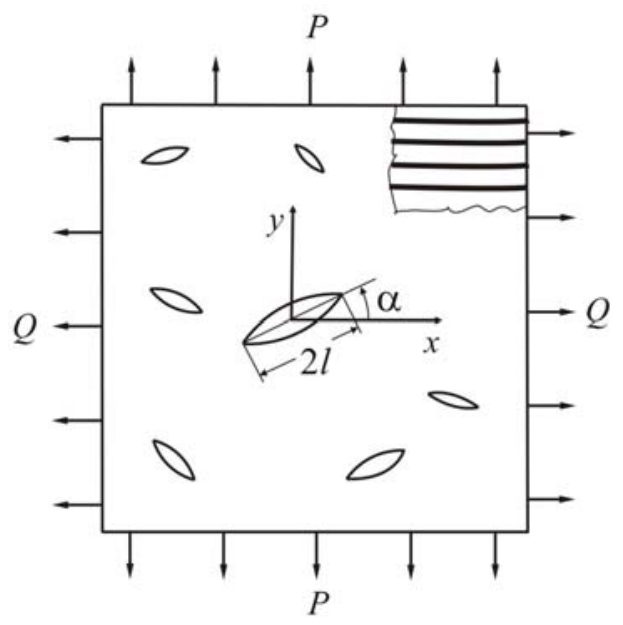

Fig. 1. Plate made of orthotropic composite material under conditions of flat deformation 
Such a material will be considered as macrohomogeneous, but anisotropic (orthotropic) in its elastic properties. The plate is under the conditions of uniformly distributed loading $P$ and $Q=\eta P$ (flat deformation). The directions of the loading action coincide with the main orthotropic directions of the material.

The structure of the material is characterized by a defect of different scales (uniform distribution of cracks that do not interact with each other). Parameters of defects (the half-length $l$ and the angle $\alpha$ between the crack line and the orthotropic axis $0 x$ ) are statistically independent random variables. Let's assume that the cracks with the most probable orientation are located in the main direction of reinforcement (the direction of the axis $0 x$ with the larger Young's modulus $E_{1}$ ). For such orientation, let's choose the distribution probability density of a random variable $\alpha$ in the form [8]

$$
f(\alpha)=\frac{\lambda^{3 / 2}}{\pi\left(\cos ^{2} \alpha+\lambda^{3} \sin ^{2} \alpha\right)}, \lambda=\frac{E_{1}}{E_{2}}>1 .
$$

Distribution density graphs (1) for different ratios of Young's modulus (various values of the parameter $\lambda$ ) are presented in Fig. 2. In particular, the value $\lambda=3,2$ corresponds to the specimen from the epoxy phenolic fiberglass EF 32-301 on the cord glass fiber TSC-VM-178 [9], for which the crack propagation along the main direction of reinforcement has been experimentally confirmed.

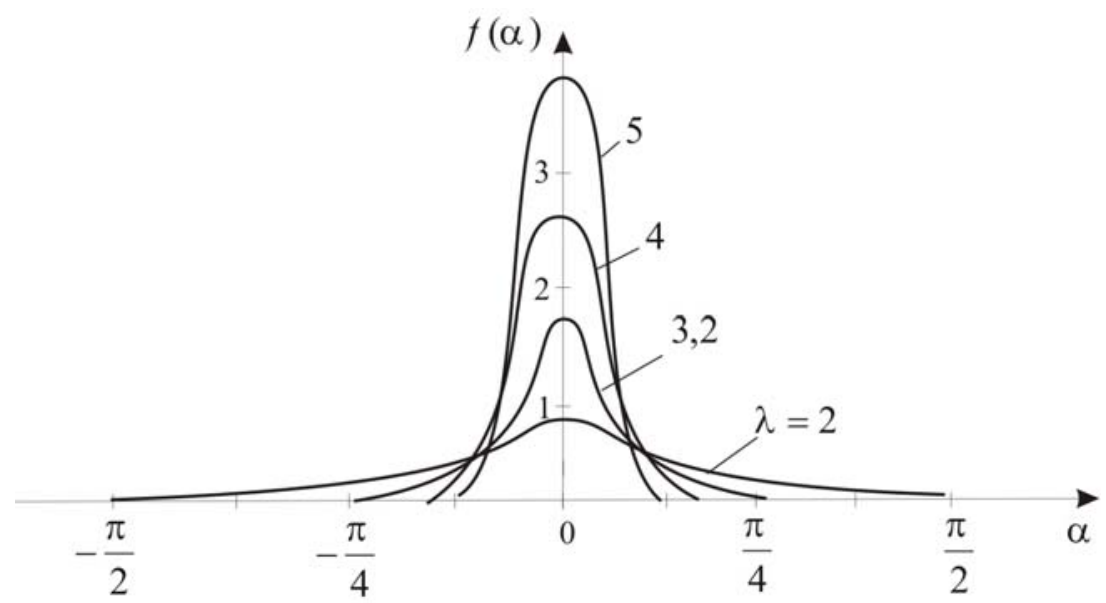

Fig. 2. Distribution probability density of random variable $\alpha$ for different values of the parameter $\lambda$

The distribution of the random variable $\alpha$ will be unimodal. The distribution density curves are symmetric with respect to the ordinate axis. As the parameter $\lambda$ increases, the most likely value $M o(\alpha)$ of the random variable is increased. In addition, with the change of the parameter $\lambda$, the shape of the distribution density curve changes.

Let's assume that the random variable $l$ varies in a a form parameter, $a$ is a scale parameter) for random variables that vary in the range from zero to infinity. As the parameter $s$ increases, the probability to meet large values of magnitude $L$ decreases. The shape of the distribution curve varies depending on the parameter $s$ change. With the increase of the random variable $L$, the graphs of the function asymptotically approach the abscissa axis. certain interval $0 \leq l \leq d$ ( $d$ is the finite structural characteristic of the material). The size of the structural element $\rho_{1}$ [10] is small in comparison with the magnitude $l$ Let's introduce a ratio $L=\rho_{1} / l$ that will be a random variable that varies in the interval: $0 \leq L<\infty$. Then let's choose the distribution probability density of a random variable $L$ in the form of a power distribution [11]

$$
\begin{aligned}
& f(L)=\frac{(s-1) a^{s-1}}{(L+a)^{s}}, \\
& s>1, a>0 .
\end{aligned}
$$

Distribution density graphs (2) are shown in Fig. 3. Distribution is a two-parameter statistical model $(s$ is

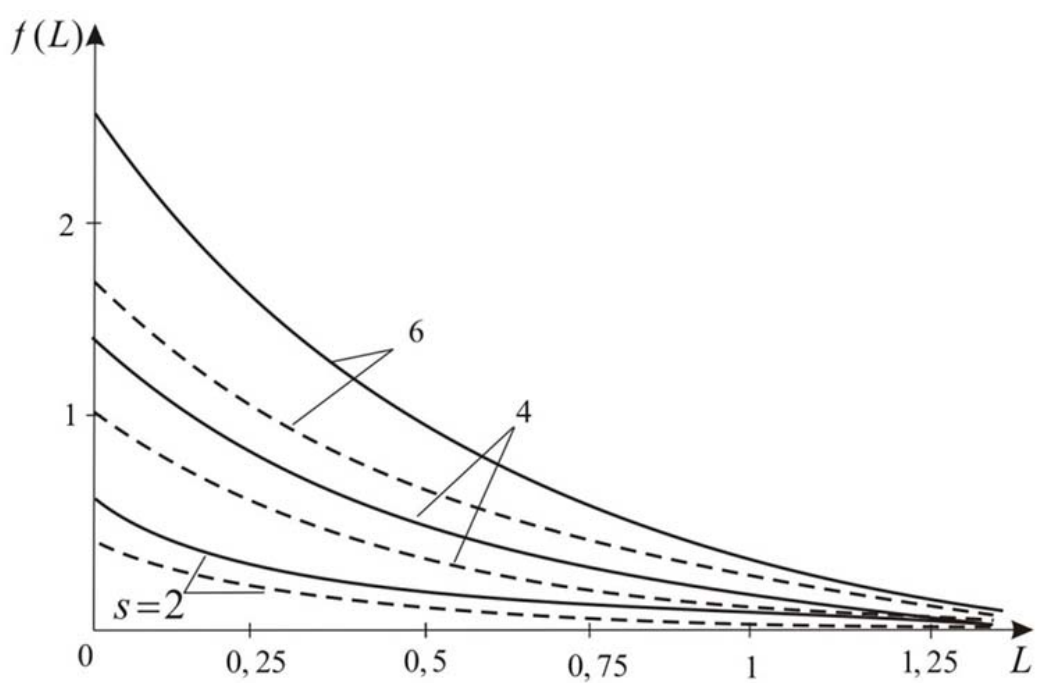

Fig. 3. Distribution probability density of random variable $L$ for different shape $s$ parameters and scale parameters (solid for $a=2$, dashed for $a=3$ ) 
In the paper [12], in accordance with the algorithm proposed in [13] and the laws of random variables distributions (1) and (2), an analytical representation of the fracture loading distribution function for a composite element with one crack is obtained

$$
\begin{aligned}
& F_{1}(P, \eta)=\frac{a^{s-1}}{\pi} \int_{-\pi / 2}^{\pi / 2} \frac{\lambda^{3 / 2}(L(P, \eta, \alpha)+a)^{1-s}}{\cos ^{2} \alpha+\lambda^{3} \sin ^{2} \alpha} d \alpha, \\
& 0 \leq P \leq P_{\max },
\end{aligned}
$$

where the value $L(P, \eta, \alpha)$ is determined from the failure criterion, which is expressed through the components of the macroscopic stresses $\left[\sigma_{i j}\right](i=1,2 ; j=1,2)$

$$
\left[\sigma_{11}\right] \sin ^{2} \alpha+\left[\sigma_{22}\right] \cos ^{2} \alpha+\left[\sigma_{12}\right] \sin 2 \alpha=\sigma_{c r},
$$

where $\sigma_{c r}$ is the strength of the composite.

For an arbitrarily oriented crack, the macroscopic stresses $\left[\sigma_{i j}\right]$ are written in the form

$$
\begin{aligned}
& {\left[\sigma_{i j}\right]=\Gamma_{i j}+\sum_{m=1}^{3}\left(\frac{\rho_{1}}{l}\right)^{\frac{m}{2}-1} \times} \\
& \times \operatorname{Re} \sum_{k=1}^{2} s_{i j}^{(k)}\left(\frac{A_{k}^{(1)} C_{k}^{(1)}}{3}+A_{k}^{(2)}+\frac{A_{k}^{(3)} C_{k}^{(3)}}{15}\right)^{;} \\
& A_{k}^{(m)}=(-1)^{m+1} \frac{(-1)^{k+1} m}{2\left(\mu_{2}-\mu_{1}\right)}\left(t_{k} D^{(1)}+D^{(2)}\right), \\
& t_{1}=\mu_{2}, t_{2}=\mu_{1} \text {; } \\
& C_{k}^{(m)}= \\
& =\frac{2^{\frac{m}{2}+1}}{a_{k} b_{k}} \frac{\rho_{2}}{\rho_{1}}\left(\left(2 a_{k}+b_{k} \frac{\rho_{2}}{\rho_{1}}\right)^{\frac{m}{2}+1}-\left(b_{k} \frac{\rho_{2}}{\rho_{1}}\right)^{\frac{m}{2}+1}-\left(2 a_{k}\right)^{\frac{m}{2}+1}\right) ;(7) \\
& a_{k}=\cos \alpha-\mu_{k} \sin \alpha, b_{k}=\sin \alpha+\mu_{k} \cos \alpha ; \\
& D^{(1)}=P \cos ^{2} \alpha+Q \sin ^{2} \alpha, \\
& D^{(2)}=\frac{P-Q}{2} \sin 2 \alpha \text {; } \\
& \Gamma_{11}=P \sin ^{2} \alpha+Q \cos ^{2} \alpha, \\
& \Gamma_{22}=P \cos ^{2} \alpha+Q \sin ^{2} \alpha \text {, } \\
& \Gamma_{12}=\frac{P-Q}{2} \sin 2 \alpha \text {; } \\
& s_{11}^{(k)}=\mu_{k}^{2}, \quad s_{22}^{(k)}=1, \quad s_{12}^{(k)}=-\mu_{k} .
\end{aligned}
$$

Here $\rho_{1}, \rho_{2}$ are the sizes of the structural element [10], which depend on the structure micro inhomogeneity, their value, type and density of distribution; $\mu_{k}$ are complex parameters, which are determined from the characteristic equation [14]

$$
\frac{\mu_{k}^{4}}{E_{1}}+\left(\frac{1}{G_{12}}-\frac{v_{12}}{E_{1}}\right) \mu_{k}^{2}+\frac{1}{E_{2}}=0, \quad k=1,2,
$$

where $v_{12}$ is Poisson's coefficient, $G_{12}$ is the shear modulus.

Taking into account the material under consideration elastic characteristics $E_{1}=50100 \mathrm{MPa}$, $E_{2}=15600 \mathrm{MPa}, v_{12}=0,25$ of the material being studied [9], let's obtain the following solutions of equation (12): $\mu_{1}=2,7874 i, \mu_{2}=0,6429 i$.

Let's use the formula to find the probability of failure of a structural element containing $N$ defects [13]

$$
P_{f}=1-\left(1-F_{1}(P, \eta)\right)^{N}, \quad 0 \leq P \leq P_{\max },
$$

which is based on the hypothesis of the weakest link.

Then the probability of failure (reliability) of an orthotropic composite material with $N$ cracks for biaxial tension-compression is determined as follows:

$$
\begin{aligned}
& P_{f}=1-\left(1-\frac{a^{s-1}}{\pi} \int_{-\pi / 2}^{\pi / 2} \frac{\lambda^{3 / 2}(L(P, \eta, \alpha)+a)^{1-s}}{\cos ^{2} \alpha+\lambda^{3} \sin ^{2} \alpha} d \alpha\right)^{N}, \\
& 0 \leq P \leq P_{\max } .
\end{aligned}
$$

According to formula (14) the dependence of the probability of failure $P_{f}$ of the researched composite (scale parameter $a=2$ ) for the various structural inhomogeneity of the material (parameter $s$ ), different number of cracks $N$, different types of loading (parameter $\eta$ ) is calculated. The corresponding diagrams are shown in Fig. 4-6.

In Fig. 4, the diagrams are shown for different types of composite stressed state at $s=5$ for uniaxial tension $(\eta=0)$, for equal biaxial tension $(\eta=1)$ and for tension-compression $(\eta=-1)$. Diagrams are constructed for different number of cracks.

Fig. 5 analyzes the dependence of the composite probability of failure on the number of cracks (dimensions of the composite) and on the structural inhomogeneity of the material for the given loading $\left(P / \sigma_{c r}=0,4\right)$.

Fig. 6 shows the dependence of the probability of failure in the fixed dimensions of the composite $(N=100)$ on the different material structural heterogeneity and for different types of loading. 


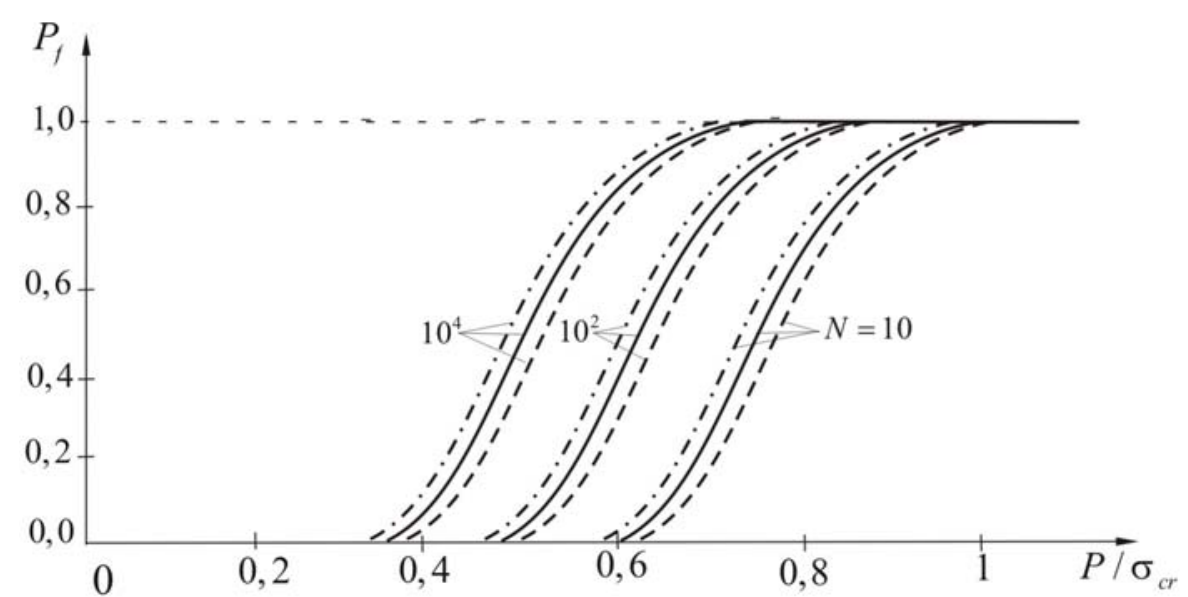

Fig. 4. Probability of failure of the composite for various types of stress state (solid for $\eta=0$, dashed for $\eta=1$, dotted dashed for $\eta=-1$ )

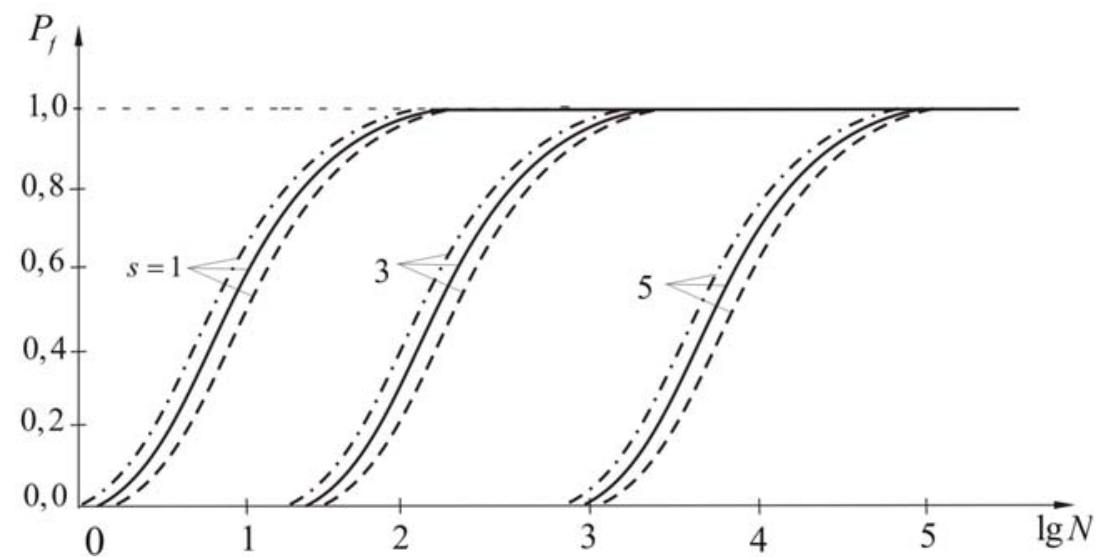

Fig. 5. Probability of failure of the composite for the given loading (solid for $\eta=0$, dashed for $\eta=1$, dotted dashed for $\eta=-1)$

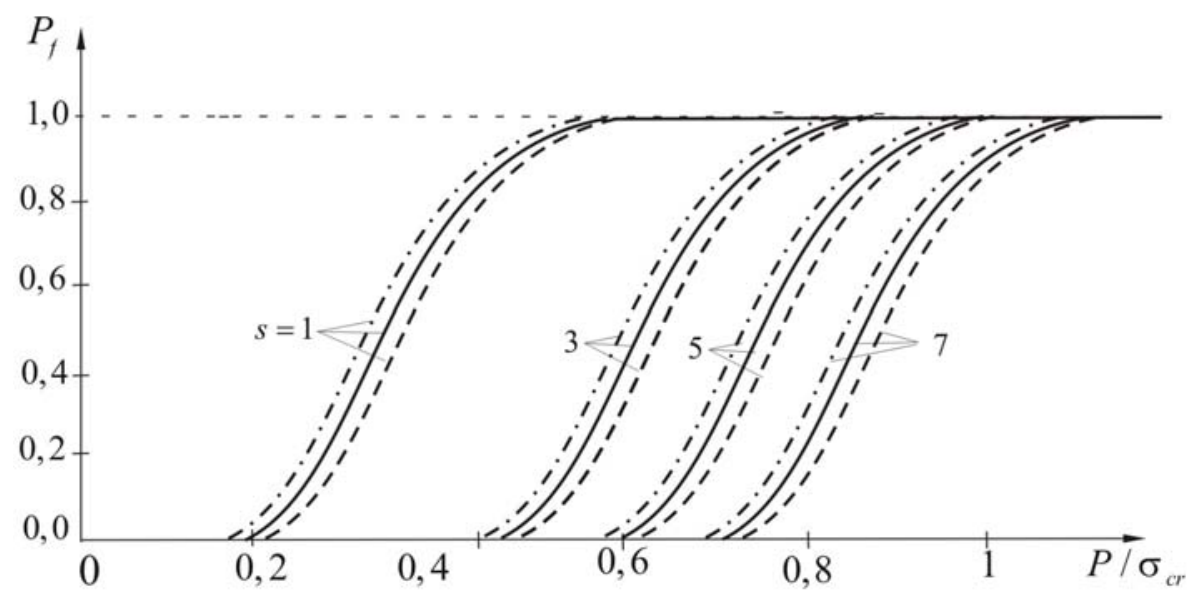

Fig. 6. Probability of failure of the composite for different material structural inhomogeneity (solid for $\eta=0$, dashed for $\eta=1$, dotted dashed for $\eta=-1$ )

\section{Research results}

In Fig. 4, it is possible to see that there is a certain range of loading, which corresponds to a low probability of failure. The probability of failure at a fixed loading increases with increasing number of cracks, and depends on the type of stressed state (on $\eta$ ).

Fig. 5 analyzes the dependence of the probability of failure on the number $N$ of cracks and the material structural inhomogeneity (parameter $s$ ) for the given loading. Each level of loading and material structural inhomogeneity corresponds to a range of composite sizes, at which the probability of its failure increases (a certain scale threshold of the probability of failure).

Fig. 6 shows the dependence of the probability of failure in the fixed dimensions of the composite ( $N=100$ ) for different material structural inhomogenei- 
ty at different types of loading. For a fixed loading with an increase in the parameter $s$ (the structure of the material goes to the homogeneous) let's obtain the pattern of decreasing the probability of failure. This pattern depends on the type of stressed state (on $\eta$ ).

\section{Conclusions}

1. The obtained distribution function of failure loading $F_{1}(P, \eta)$ has all the properties of the integral distribution function of the random variable.

2. The composite probability of failure $P_{f}$ depends on the type of applied loading, the number of defects and the structural inhomogeneity of the material.
3. There are certain intervals of the applied loading and the composite dimensions, in which observe a significant increase in the probability of failure $P_{f}$.

4. The highest reliability of the investigated material is observed for equal biaxial tension, the smallest for tension-compression. This pattern is a consequence of the material orthotropic influence. Since, according to the proposed model, the orientation of defects in the direction of reinforcement is prevalent (the physical content of the law (1)), therefore, in the case of equal biaxial tension, the loading action $Q$ causes the cracks closing and the increasing in the material strength, and hence the probability of failure $P_{f}$ growth.

\section{References}

1. Barbero E., Fernández-Sáez J., Navarro C. Statistical analysis of the mechanical properties of composite materials // Composites Part B: Engineering. 2000. Vol. 31, Issue 5. P. 375-381. doi: https://doi.org/10.1016/s1359-8368(00)00027-5

2. Dirikolu M., Aktas A., Birgoren B. Statistical analysis of fracture strength of composite materials using Weibull distribution // Turkish Journal of Engineering and Environmental Sciences. 2002. Vol. 26, Issue 1. P. 45-48.

3. Sakin R., Ay İ. Statistical analysis of bending fatigue life data using Weibull distribution in glass-fiber reinforced polyester composites // Materials \& Design. 2008. Vol. 29, Issue 6. P. 1170-1181. doi: https://doi.org/10.1016/j.matdes.2007.05.005

4. Kolios A. J., Proia S. Evaluation of the Reliability Performance of Failure Criteria for Composite Structures // World Journal of Mechanics. 2012. Vol. 02, Issue 03. P. 162-170. doi: https://doi.org/10.4236/wjm.2012.23019

5. Khoroshun L. P., Nazarenko L. V. Deformation and Damage of Composites with Anisotropic Components (Review) // International Applied Mechanics. 2013. Vol. 49, Issue 4. P. 388-455. doi: https://doi.org/10.1007/s10778-013-0578-6

6. Balasubramanian M. Statistical analysis of tensile strength and elongation of pulse TIG welded titanium alloy joints using Weibull distribution // Cogent Engineering. 2016. Vol. 3, Issue 1. doi: https://doi.org/10.1080/23311916.2016.1239298

7. Naresh K., Shankar K., Velmurugan R. Reliability analysis of tensile strengths using Weibull distribution in glass/epoxy and carbon/epoxy composites // Composites Part B: Engineering. 2018. Vol. 133. P. 129-144. doi: https://doi.org/10.1016/ j.compositesb.2017.09.002

8. Kvit R., Krupka Z. Determination of the orthotropic composite materials strength statistical characteristics // Bulletin of the Lviv Polytechnic State University. Physical and Mathematical Sciences. 1997. P. 85-87.

9. Serensen S., Zaitsev G. Bearing capacity of thin-walled structures made of reinforced plastics with defects. Kyiv, 1982.295 p.

10. Deliavskyi M., Kvit R. Macro-stress distribution near crack-like defects in anisotropic micro-inhomogeneous body under flat deformation and longitudinal displacement // Physicochemical Mechanics of Materials. 1992. Vol. 2. P. 50-54.

11. A manual on probability theory and mathematical statistics / Korolyuk V. et. al. Moscow, 1985. 640 p.

12. Kvit R. A statistical approach to the assessment of the reliability of structural materials // Bulletin of the Lviv Polytechnic National University. Physical and Mathematical Sciences. 2000. P. 93-96.

13. Vytvytsky P., Popina S. Strength and criteria of brittle fracture of stochastically defective bodies. Kyiv, 1980. $186 \mathrm{p}$.

14. Sih G. C., Liebowitz H. Mathematical theory of brittle fracture. Fracture. Vol. 2. Moscow, 1975. P. 83-203.

Дата надходження рукопису 30.08.2018

Roman Baitsar, Doctor of Technical Sciences, Professor, Department of Measuring Information Technologies, Lviv Polytechnic National University, S. Bandery str., 12, Lviv, Ukraine, 79013

E-mail: baitsar@ukr.net

Roman Kvit, PhD, Associate Professor, Department of Mathematics, Lviv Polytechnic National University, S. Bandery str., 12, Lviv, Ukraine, 79013

E-mail: kvit_rom@ukr.net 